\title{
Hysteresis curve simulation of RC frame based on finite element software ABAQUS
}

\author{
Wenqiang Wang ${ }^{1, a}$, Tieying $\mathrm{Li}^{1, \mathrm{~b}}$ \\ ${ }^{1}$ Department of Civil Engineering, Taiyuan University of Technology \\ 79, Yingzexi Street, Taiyuan, 030024, China \\ awwq19871120@163.com, ' Ity680412@163.com
}

Keywords: RC structure; ABAQUS; deformation characteristic; energy dissipation characteristic

\begin{abstract}
This paper using the finite element software of ABAQUS to simulate a $\mathrm{RC}$ frame deformation characteristics and energy dissipation characteristics when the loading posi- tion is different.
\end{abstract}

\section{Introduction}

In 1872, the first reinforced concrete structure of the building in New York was completed and the human history of a new era began from then on. The reinforced concrete structure got the large-scale use in engineering fang in the1900 years later. In 1928, the prestressed reinforced concrete which is a new type of reinforced concrete structure form was invented, and it has also been widely used in the engineering practice in the second world war. The invention of the reinforced concrete and the application of the steel products in construction in the 19 centuries middle period makes the high-rise buildings and the large span bridge to be built.

At present in our country, the reinforced concrete application is a kind of most structure form. Our country's annual amount of the concrete is about nine hundred million cubic meters, and the reinforced dosage is about 20 million tons. According to the calculation, the concrete structure construction in China only a year costs 200 billion yuan of above. Since it has use local materials, good durability and fire resistance, good entirety and normability, the steel dosage is less than the steel structure, the reinforced concrete will be a kind of important engineering structural materials in our country from now on. This paper using the finite element software of ABAQUS to simulate a $\mathrm{RC}$ frame stress state under the horizontal loads, draw the hysteresis curve of the different load position, and make a simple comparison.

\section{ABAQUS software introduction}

ABAQUS was founded by David Habbitt Bengt karlsson and Paul Sorensen in 1978. it is a set of advanced general finite element system, which is also one of the strongest function finite element software. It can also controls the very large and complex and highly nonlinear simulation. ABAQUS not only can does a single component of mechanics and analysis of the physical field, but also can completes system level analysis and research. Because of the strong analysis ability and the reliability of complex system simulation, ABAQUS has been widely used in the study and industry by all over the world, and it plays a tremendous role in the large number of high-tech product development.

ABAQUS has two main analysis modules: ABAQUS/Standard provides general analysis ability, such as stress and deformation, heat transfer, mass transfer, etc; ABAQUS/Explicit is used to the explicit integral and solve dynamic equation for time, and it provides the powerful tool for dealing with the complex contact problem. It is mainly used to solve the high speed dynamics problems, such as collision, drop, explosion, etc.

\section{The finite element analysis}

Choose unit types 
This paper's model is built by the reinforcement and concrete which is the two completely different material. This paper is mainly concerned with the $\mathrm{RC}$ structure mechanical characteristics. refer to the manual ABAQUS unit, the beam and column using the entity elements analysis, and all the steel using the truss elements analysis.

\section{Define material}

Because of the two different material, this paper needs separate definit two material characteristics for concrete and steel reinforced. The reinforced material properties: elastic modulus $\mathrm{E}=1.9 \mathrm{e} 11 \mathrm{~N} / \mathrm{m} 2$, poisson ratio $\mu=0.3$, yield strength fy $=2.1 \mathrm{e} 8 \mathrm{~s} \mathrm{~N} / \mathrm{m} 2$; The concrete elastic modulus $\mathrm{E}=2.95$ was $\mathrm{N} / \mathrm{m} 2$, poisson ratio $\mu=0.2$. In this article, the plastic concrete damage model will be used to analyze the characteristics of plastic concrete.

\section{Geometric modeling}

The three dimensional analysis model will be used in this paper. A three layers RC frame structure with 3 meters floor height and 4 meters column space will be built in this article. the concrete cover depth: column $\mathrm{C}=30 \mathrm{~mm}$; beam $\mathrm{C}=25 \mathrm{~mm}$. The column section is $400 \mathrm{x} 400$, and the longitudinal force reinforced is $4 \mathrm{C} 22$, and the stirrup is $\Phi 8 @ 150$; The beam section is 300 $\mathrm{x} 200$, and the pressure reinforced is $2 \mathrm{C} 16$ in the top, and the tensile steel is $3 \mathrm{C} 16$ in the bottom, and the stirrup is $\Phi 8 @ 200$. The model in this paper are as follows:

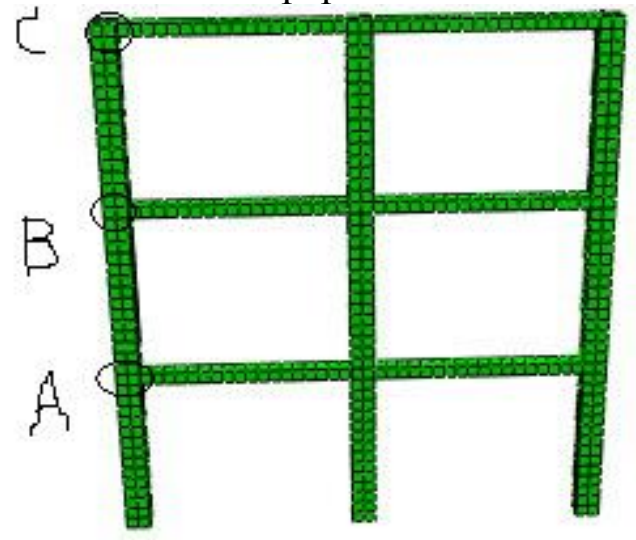

\section{Load application}

Figure 1 The RC frame modeling schemes with three layers

This analysis sets two analysis steps: The first analysis step sets the connection form of the RC frame column bottom is consolidation; The second step in the model analysis draws the different hysteresis curve when the horizontal displacement loads places on the point of A, B and C. This analysis for horizontal displacement load are as follows:

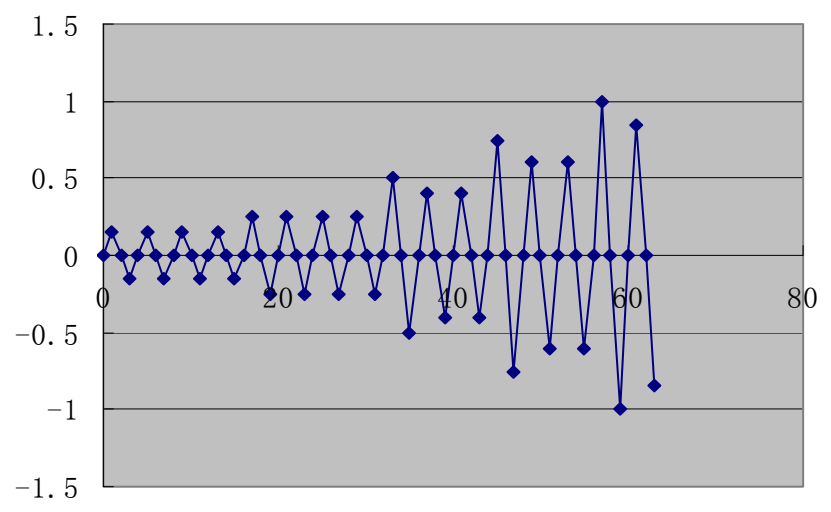

\section{Post-processing}

Figure 2 Horizontal displacement load curve

Creating a analysis work and submit, and clicking into the post-processing module after the completion of the analysis. When the loading position places on $\mathrm{A}, \mathrm{B}$ and $\mathrm{C}$ respectively, the hysteresis curve as follows:

(1) when loading point for point A, the hysteresis curve as follows: 


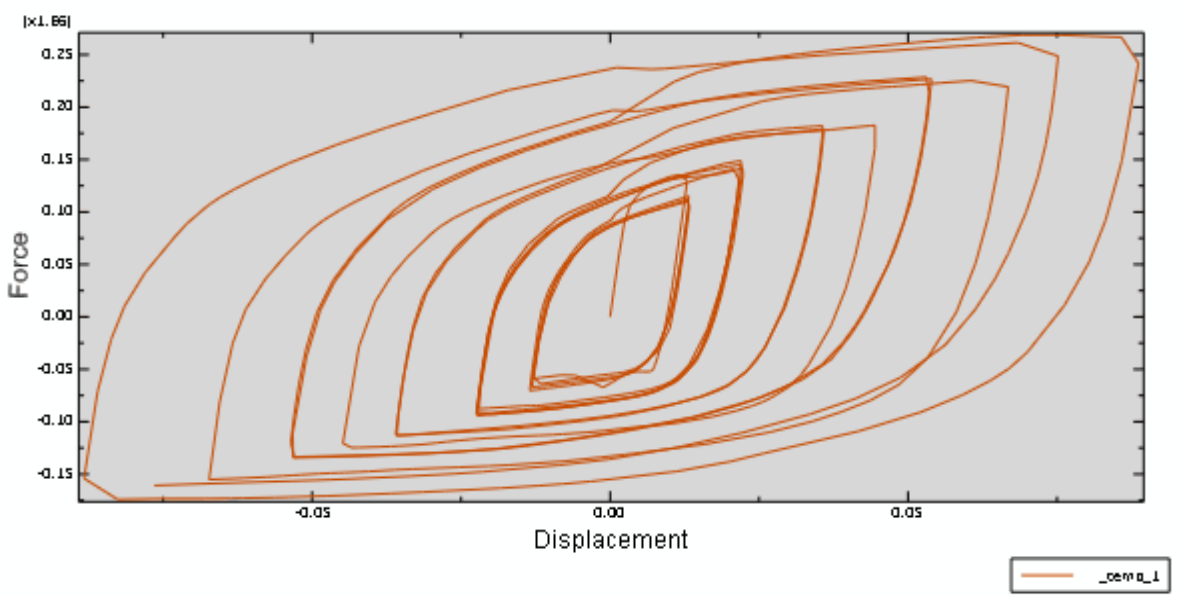

Figure 3 The hysteresis curve of point A

(2) when loading point for point $\mathrm{B}$, the hysteresis curve as follows:

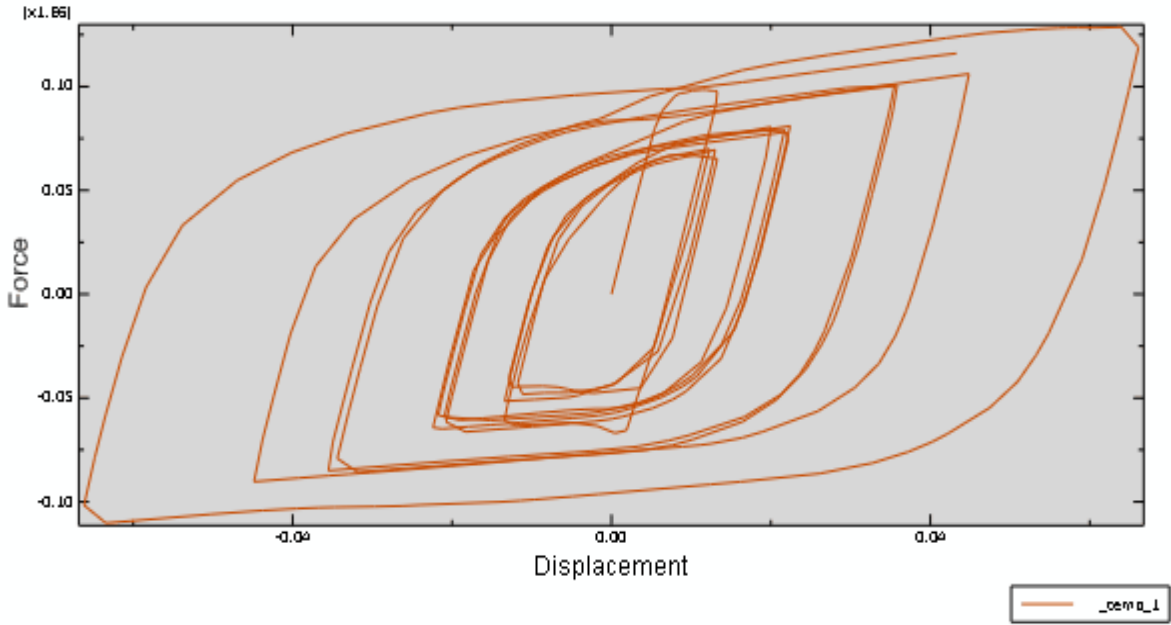

Figure 4 The hysteresis curve of point $\mathrm{B}$

(3) when loading point for point $\mathrm{C}$, the hysteresis curve as follows:

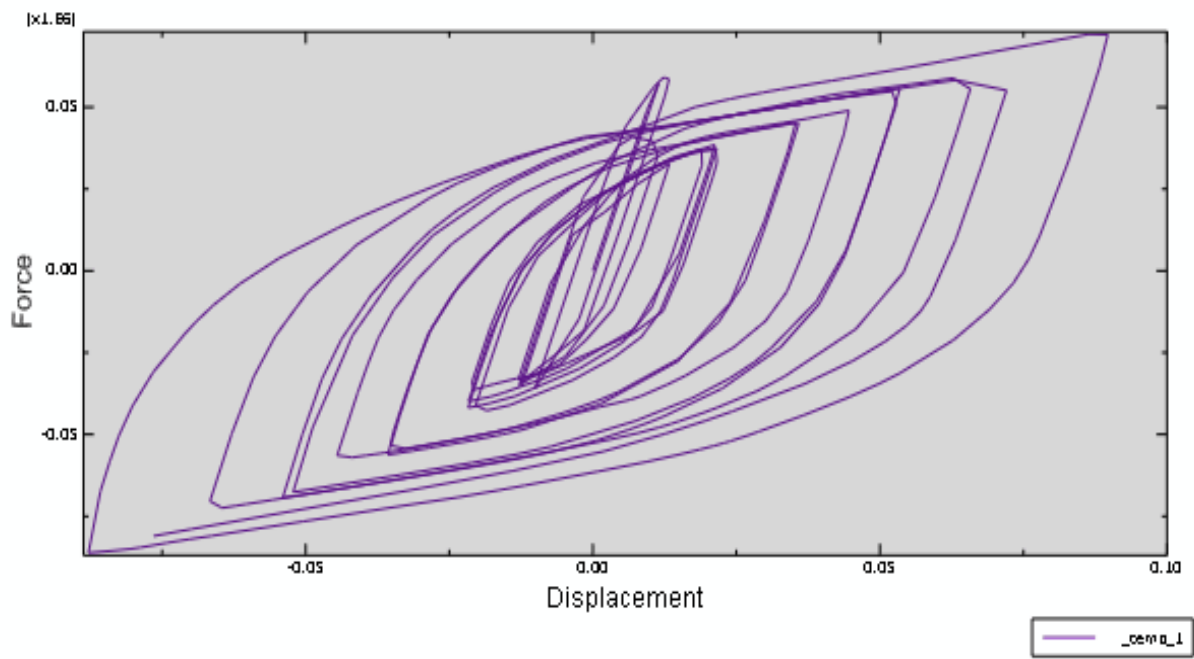

Figure 5 The hysteresis curve of point $\mathrm{C}$

\section{Summary}

From the above analysis, It can be seen that the ABAQUS finite element analysis software can simulates the hysteresis curve of RC frame structure well in the horizontal displacement loads. The above three hysteresis curve shape are "spindle", explaining that the RC structure has good plastic 
deformation ability, seismic performance and energy dissipation capacity. By comparing A, B and C three lag circle area can be concluded that: the RC frame structure's plastic deformation ability and energy dissipation capacity are more and more weak from bottom to top. And get that: The reinforced concrete frame structure's damage mainly concentrated in the lower part of the structure, Therefore, we should pay more attention to the lower parts of the structure in the seismic design.

\section{Acknowledgements}

This research is supported by National Natural Science Foundation of China (No. 50978178). The corresponding author is Tieying Li. We are very grateful to all the reviewers for their constructive comments on this paper.

\section{References}

[1] Y.P.Shi and Y.R.Zhou. The detailed examples of ABAQUS finite element analysis[M]. ( Machinery Industry Publishers, Beijing, 2006).

[2] J.F.Cao and Y.P.Shi. ABAQUS finite element analysis FAQ[M]. (Machinery Industry Publishers, Beijing, 2009).

[3] SIMWE simulation Forum http://forum.simwe.com/index.php.

[4] Y.Z.Wang and C.G.Fu. Analysis of structural engineering and example explanation[M] (China Building Industry Publishers, Beijing,2010). 